\title{
White fat, factitious hyperglycemia, and the role of FDG PET to enhance understanding of adipocyte metabolism
}

\author{
Michael S Hofman ${ }^{1,2^{*}}$ and Rodney J Hicks ${ }^{1,2}$
}

\begin{abstract}
The development of a hybrid PET/CT led to the recognition of the enhanced glycolysis in brown fat. We report a previously unrecognized mechanism for altered fluorodeoxyglucose (FDG) biodistribution with diffuse white adipose tissue uptake. This occurred during a restaging scan for cervical cancer following administration of insulin in the setting of measured hyperglycemia. The patient's blood sugar normalized, but she experienced symptoms and signs of hypoglycemia. A subsequent history indicated that the patient received intravenous high-dose vitamin C just prior to arrival. Ascorbic acid is a strong reducing agent and can cause erroneous false positive portable glucometer readings. Accordingly, it is likely the patient was euglycemic on arrival and was administered FDG during a period of insulin-induced hypoglycemia. Prominent diffuse white adipose tissue, gastric mucosal, myocardial, and very low hepatic and muscle activity were observed. The case provides insight into the metabolic changes that occur during hypoglycemia and the potential danger of relying on portable glucometer readings. We discuss the potential biological basis of this finding and provide recommendations on the avoidance of this complication.
\end{abstract}

\section{Background}

The development of hybrid positron emission tomography/computed tomography (PET/CT) devices led to the recognition of enhanced glycolysis in brown fat, typically in the neck and paravertebral regions of the thorax and upper abdomen, as a thermoregulatory response and under catecholamine stimulation [1-3]. Other atypical patterns of fat uptake in patients with lipodystrophy have been reported $[2,3]$ We report a previously unrecognized mechanism for altered fluorodeoxyglucose (FDG) biodistribution into adipose tissues.

\section{Case presentation}

A 40-year-old woman presented for restaging with F-18 FDG PET/CT on the background of squamous cell carcinoma of the cervix and biopsy proven recurrence in a left supraclavicular node. Conventional imaging had demonstrated no further evidence of metastatic disease. She had previously received radical chemoradiotherapy

\footnotetext{
* Correspondence: michael.hofman@petermac.org

${ }^{1}$ Center for Cancer Imaging, Peter MacCallum Cancer Centre, St. Andrews

Place, East Melbourne, VIC 3002 Australia

Full list of author information is available at the end of the article
}

for FIGO stage IIIb disease with para-aortic nodal involvement, without intervening therapy in the 6 months since completing the treatment. The patient was not diabetic and had a body mass index of 24 , which is in the normal range for a female. She had no other past medical history, took no medications, and had fasted from the previous evening.

On arrival, her blood glucose level (BGL) obtained with a portable glucometer (Abbott Diabetes Care Optium Xceed, Alameda, CA, USA) via a fingerprick capillary blood sample was $15 \mathrm{mmol} / \mathrm{L}$, and she was administered $6 \mathrm{U}$ of short-acting insulin intravenously as per local protocol. Thirty minutes later, her BGL had fallen to $6.9 \mathrm{mmol} / \mathrm{L}$, and she described feeling unwell with anxiety, palpitations, and sweating. Her blood pressure, temperature, and oxygen saturation levels were normal, and she was observed. The BGL measurements plateaued at $6.0 \mathrm{mmol} / \mathrm{L}$, and FDG was subsequently injected. PET/CT scanning was performed 60 min later.

The images demonstrated altered biodistribution of FDG with a prominent uptake of the radiotracer throughout white adipose tissue (WAT), gastric mucosa, myocardium and very low hepatic activity (standardized 
uptake value (SUVmax) 2.3, 5.0, 16, and 1.2, respectively) (Figure 1). WAT was most prominent in intraabdominal (mesenteric) fat. There was negligible muscle uptake (SUVmax, 1.0).

Given this unusual biodistribution, we questioned the patient further. She reported receiving an intravenous infusion of high-dose vitamin $\mathrm{C}$ (sodium ascorbate solution) from another health practitioner just prior to her arrival for the PET scan. Ascorbic acid is a strong reducing agent and interferes with laboratory tests involving oxidation and reduction reactions. Substantially reduced or elevated portable glucometer readings occur with ascorbic acid in a dose-dependent fashion and is one of the most common interfering substances that affects the accuracy of glucose meters $[4,5]$. A plasma venous sample was not available to confirm either plasma glucose or ascorbic acid as blood was obtained via fingerprick, and the error was not suspected prospectively. Nevertheless, the clinical symptoms of hypoglycemia and a history of intravenous ascorbic acid just prior to arrival at the PET scan, provides sufficient evidence to indicate that the patient was injected with FDG during a period of iatrogenic hypoglycemia induced by administration of insulin in the setting of a falsely elevated BGL reading.

Based on the unusual pattern of uptake, the study was repeated the following day in the absence of vitamin $C$. BGL was normal on arrival, and the FDG biodistribution was normal on the repeat study (see Figure 2; Additional file 1).

\section{Discussion}

This case highlights the potential limitations of standardized insulin protocols [6,7], especially when relying on point-of-care glucometers. Intravenous ascorbic acid may result in substantial error in glucometer readings $[4,5]$. This is of particular relevance for cancer imaging as some complementary care practitioners advocate the use of vitamin $\mathrm{C}$ in conjunction with chemotherapy or radiotherapy in a wide variety of malignancies [8]; moreover, many patients choose not to tell their doctors about concomitant use of alternative medicines [9]. Clinicians should also be aware of other potential causes of error resulting in factitious hyperglycemia including substances containing maltose (e.g., intravenous human immunoglobulin) [10], icodextrin (e.g., peritoneal dialysis solution) [11] and galactose. Indeed, several deaths have been reported, and warnings have been issued by health regulatory agencies [12-15]. Accordingly, a patient should be questioned regarding the use of not only conventional chemotherapy and mediations but also whether they are having alternative therapies.

The case also illustrates a remarkable pattern of prominent WAT glycolytic activity on FDG PET. We hypothesize that this was likely physiologic and in

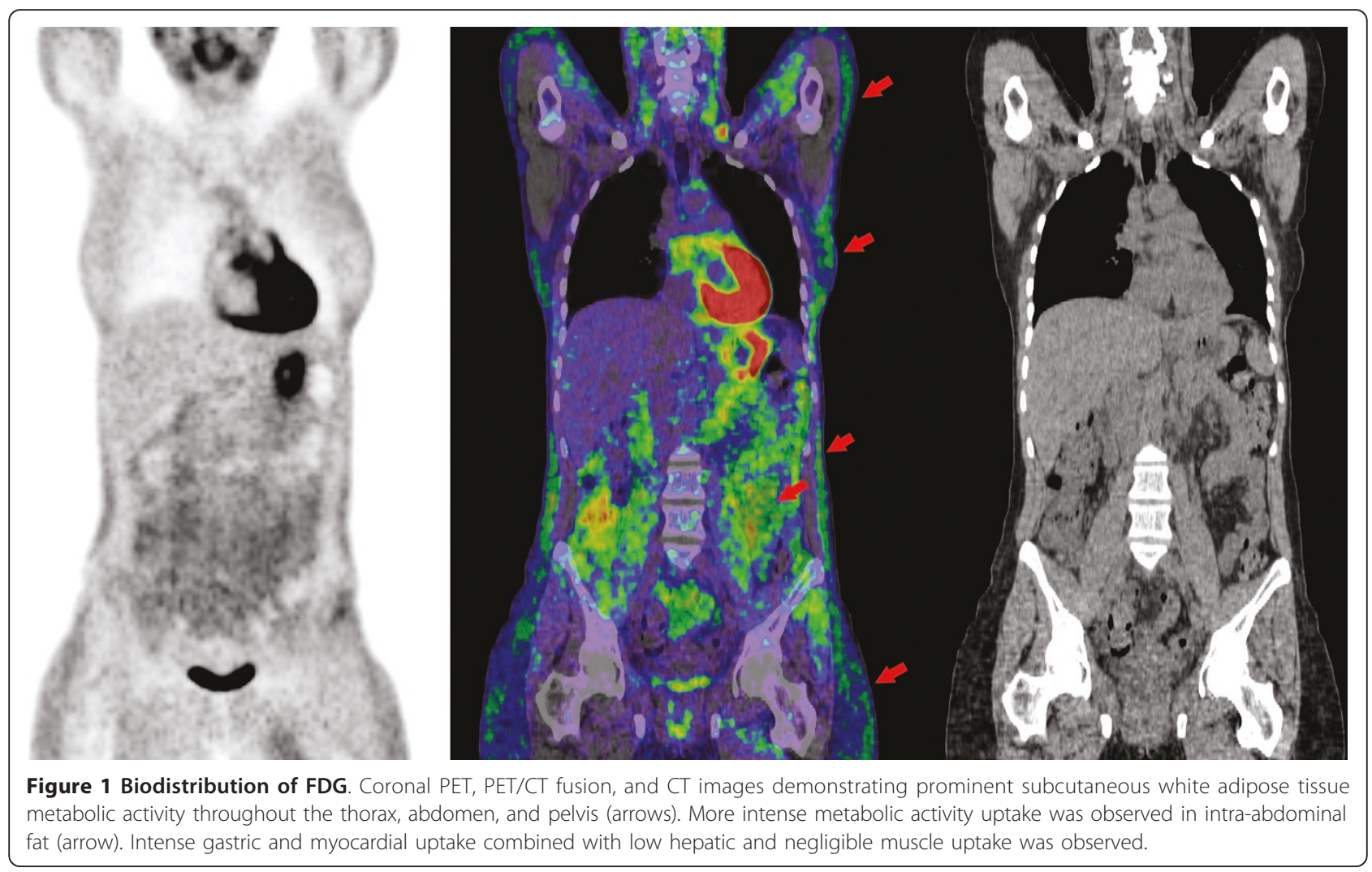




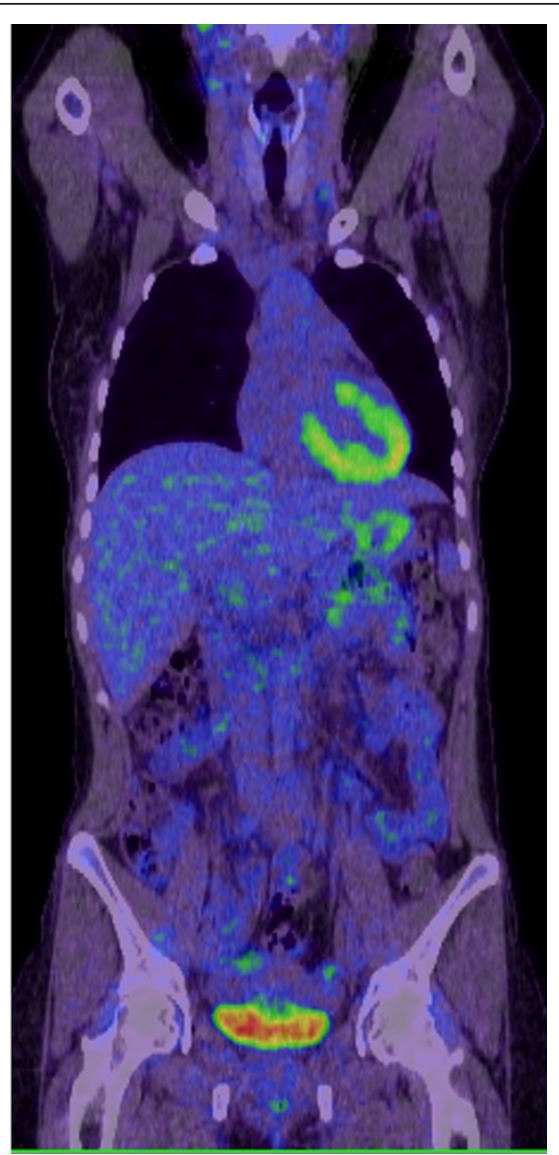

Figure 2 Results of repeated study on biodistribution of FDG. Coronal PET and PET/CT fusion images demonstrating normal distribution of FDG in the study performed the following day when normoglycemic in the absence of prior ascorbic acid or exogenous insulin.

response to hypoglycemia induced by administration of insulin. This is different than the characteristic pattern of diffuse muscular uptake visualized in hyperinsulinemic patients, during hyperinsulinemic euglycemic clamping or following oral glucose loading for optimization of cardiac imaging [16], or in nonfasted or hyperglycemic patients undergoing oncologic imaging [6]. It is also different than the pattern of FDG uptake observed in brown fat adipose tissue in cervical, supraclavicular, paravertebral regions, mediastinal, and suprarenal regions [1-3].

During hypoglycemia, major changes in metabolism occur, including mobilization of liver glycogen and release of energy stored in WAT into circulation as nonesterified fatty acids. Our findings demonstrate relative high-glucose uptake into adipocytes in response to hypoglycemia in a distribution consistent with WAT activation. The two main defenses to hypoglycemia are an increase in glucagon secretion and adrenaline secretion [17]. Glucagon, secreted by pancreatic $\alpha$-cells, results in the stimulation of adenylate cyclase activity within adipocytes and plays the primary role in counter hormone regulation by promoting lipolysis in WAT [18-20]. Lipolysis also occurs via adrenaline released from the sympathetic nervous system terminals innervating WAT [21]. Catecholamines also activate brown fat with beta-blockers having been advocated as an intervention to reduce this confounding finding on FDG PET in predisposed individuals [22]. Other growth hormones such as FGF-21 may also play role. FGF-21 has been shown to stimulate glucose uptake in adipocytes and suppress hepatic glucose production [23]. Elevated FGF-21 levels have also been described in patients with HIV-associated lipodystrophy [24], where atypical FDG fat distribution is also described $[25,26]$.

An additional hypothesis is that high-dose ascorbic acid administered in a short time period prior to the study is responsible, possibly in part, for the observed increased WAT glycolytic activity. Ascorbic acid dietary supplementation has been shown to reduce abdominal and subcutaneous fat depots in high-fat diet-induced adiposity animal models [27]. This study demonstrated upregulation of genes involved in cell proliferation and downregulation of genes participating in lipid 
metabolism and steroidogenesis in rats supplemented with ascorbic acid.

At the sites of increased WAT metabolic activity, a higher Hounsfield unit (HU) on CT was observed in the same region of WAT compared to the study performed one day later. Although not visually discernable, HU averaged -71 within WAT compared to -86 on the second scan, with an identical HU in other tissues such as muscle. This phenomenon has been described in brown adipose tissue (BAT) but, to the best of our knowledge, has not been described before in WAT. A prior animal and patient study demonstrated that the total lipid content of BAT was substantially decreased when activated under cold conditions, with a corresponding increase in CT HUs [28]. In this case, a rapid consumption of stored lipid within WAT may also account for the change seen. Greater blood flow in activated fat may also contribute to the rise in $\mathrm{HU}$ [29].

\section{Conclusion}

FDG PET/CT is a useful noninvasive imaging modality for visualizing metabolic changes within adipocytes. A greater understanding of the role of both brown and white adipocyte tissue as endocrine organs is of public health interest as they may be central to our improved understanding of obesity and diabetes mellitus [30]. The mechanisms of observed WAT glycolytic activity in this case study are proposed but uncertain. In particular, the role of exogenous insulin, physiologic hormonal responses to hypoglycemia or ascorbic acid in inducing WAT glycolytic activity is uncertain. Further controlled studies utilizing FDG and tracers that interrogate other metabolic and receptor pathways may enhance our understanding of endocrine pathophysiology.

\section{Consent}

Written informed consent was obtained from the patient for the publication of this manuscript and accompanying images. A copy of the written consent is available for review by the Editor-in-Chief of this journal.

\section{Additional material}

Additional file 1: Comparative rotating maximum intensity projection images demonstrating altered FDG biodistribution on the first study (right), with normalization on FDG biodistribution when repeated the following day in the absence of prior ascorbic acid or exogenous insulin (left).

\section{Author details}

${ }^{1}$ Center for Cancer Imaging, Peter MacCallum Cancer Centre, St. Andrews Place, East Melbourne, VIC 3002 Australia ${ }^{2}$ Departments of Medicine and Radiology, University of Melbourne, Melbourne, VIC Australia

\section{Authors' contributions}

MSH and RJH both made contributions to conception and design, drafting, and revising the manuscript. All authors read and approved the final manuscript.

\section{Competing interests}

The authors declare that they have no competing interests.

Received: 16 February 2011 Accepted: 7 June 2011

Published: 7 June 2011

\section{References}

1. Cohade C, Osman M, Pannu HK, Wahl RL: Uptake in supraclavicular area fat ("USA-Fat"): description on 18F-FDG PET/CT. J Nucl Med 2003, 44:170-176.

2. Hany TF, Gharehpapagh E, Kamel EM, Buck A, Himms-Hagen J, von Schulthess GK: Brown adipose tissue: a factor to consider in symmetrical tracer uptake in the neck and upper chest region. Eur J Nucl Med Mol Imaging 2002, 29:1393-1398.

3. Cypess AM, Lehman S, Williams G, Tal I, Rodman D, Goldfine AB, Kuo FC, Palmer EL, Tseng YH, Doria A, Kolodny GM, Kahn CR: Identification and importance of brown adipose tissue in adult humans. N Engl J Med 2009, 360:1509-1517.

4. Tang Z, Du X, Louie RF, Kost GJ: Effects of drugs on glucose measurements with handheld glucose meters and a portable glucose analyzer. Am J Clin Pathol 2000, 113:75-86.

5. Siest G, Appel W, Blijenberg GB, Capolaghi B, Galteau MM, Heusghem C, Hjelm M, Lauer KL, Le Perron B, Loppinet V, Love C, Royer RJ, Tognoni C, Wilding P: Drug interference in clinical chemistry: studies on ascorbic acid. J Clin Chem Clin Biochem 1978, 16:103-110.

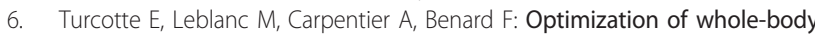
positron emission tomography imaging by using delayed 2-deoxy-2-[F18]fluoro-D: -glucose Injection following I.V. Insulin in diabetic patients. Mol Imaging Biol 2006, 8:348-354.

7. Roy FN, Beaulieu S, Boucher L, Bourdeau I, Cohade C: Impact of intravenous insulin on 18F-FDG PET in diabetic cancer patients. J NuCl Med 2009, 50:178-183.

8. Chen Q, Espey MG, Sun AY, Pooput C, Kirk KL, Krishna MC, Khosh DB, Drisko J, Levine M: Pharmacologic doses of ascorbate act as a prooxidant and decrease growth of aggressive tumor xenografts in mice. Proc Natl Acad Sci USA 2008, 105:11105-11109.

9. Eisenberg DM, Davis RB, Ettner SL, Appel S, Wilkey S, Van Rompay M, Kessler RC: Trends in alternative medicine use in the United States, 19901997: results of a follow-up national survey. JAMA 1998, 280:1569-1575.

10. Kannan S, Rowland CH, Hockings Gl, Tauchmann PM: Intragam can interfere with blood glucose monitoring. Med J Aust 2004, 180:251-252.

11. Korsatko S, Ellmerer M, Schaupp L, Mader JK, Smolle KH, Tiran B, Plank J: Hypoglycaemic coma due to falsely high point-of-care glucose measurements in an ICU-patient with peritoneal dialysis: a critical incidence report. Intensive Care Med 2009, 35:571-572.

12. Schleis TG: Interference of maltose, icodextrin, galactose, or xylose with some blood glucose monitoring systems. Pharmacotherapy 2007, 27:1313-1321.

13. Medicines and Healthcare Products Regulatory Agency, Medical Device Alert MDA/2003/001. [http://glucosesafety.com/uk/pdf/MDA-2007-058\% 20updated.pdf].

14. Kaufmann PA, Di Carli MF: Hybrid SPECT/CT and PET/CT imaging: the next step in noninvasive cardiac imaging. Semin NuCl Med 2009, 39:341-347.

15. Kirrane BM, Duthie EA, Nelson LS: Unrecognized hypoglycemia due to maltodextrin interference with bedside glucometry. J Med Toxicol 2009 5:20-23.

16. vom Dahl J, Herman WH, Hicks RJ, Ortiz-Alonso FJ, Lee KS, Allman KC, Wolfe ER, Kalff $V$, Schwaiger M: Myocardial glucose uptake in patients with insulin-dependent diabetes mellitus assessed quantitatively by dynamic positron emission tomography. Circulation 1993, 88:395-404.

17. Cryer PE, Gerich JE: Glucose counterregulation, hypoglycemia, and intensive insulin therapy in diabetes mellitus. N Engl J Med 1985, 313:232-241. 
18. Habegger KM, Heppner KM, Geary N, Bartness TJ, DiMarchi R, Tschop MH: The metabolic actions of glucagon revisited. Nat Rev Endocrinol 2010, 6:689-697.

19. Tesfaye N, Seaquist ER: Neuroendocrine responses to hypoglycemia. Ann N Y Acad Sci 2010, 1212:12-28.

20. Perea A, Clemente F, Martinell J, Villanueva-Penacarrillo ML, Valverde I: Physiological effect of glucagon in human isolated adipocytes. Horm Metab Res 1995, 27:372-375.

21. Brito NA, Brito MN, Bartness TJ: Differential sympathetic drive to adipose tissues after food deprivation, cold exposure or glucoprivation. Am J Physiol Regul Integr Comp Physiol 2008, 294:R1445-1452.

22. Parysow O, Mollerach AM, Jager V, Racioppi S, San Roman J, Gerbaudo VH: Low-dose oral propranolol could reduce brown adipose tissue F-18 FDG uptake in patients undergoing PET scans. Clin Nucl Med 2007, 32:351-357.

23. Xu J, Stanislaus S, Chinookoswong N, Lau YY, Hager T, Patel J, Ge H, Weiszmann J, Lu SC, Graham M, Busby J, Hecht R, Li YS, Lindberg RA, Veniant MM: Acute glucose-lowering and insulin-sensitizing action of FGF21 in insulin resistant mouse models - association with liver and adipose tissue effects. Am J Physiol Endocrinol Metab 2009.

24. Domingo P, Gallego-Escuredo JM, Domingo JC, Gutierrez Mdel M, Mateo MG, Fernandez I, Vidal F, Giralt M, Villarroya F: Serum FGF21 levels are elevated in association with lipodystrophy, insulin resistance and biomarkers of liver injury in HIV-1-infected patients. AIDS 2010, 24:2629-2637.

25. Sathekge M, Maes A, Kgomo M, Stolz A, Ankrah A, Van de Wiele C: Evaluation of glucose uptake by skeletal muscle tissue and subcutaneous fat in HIV-infected patients with and without lipodystrophy using FDG-PET. Nucl Med Commun 2010, 31:311-314

26. Clarke JR, Brglevska S, Lau EW, Ramdave S, Hicks RJ: Atypical brown fat distribution in young males demonstrated on PET/CT. Clin Nucl Med 2007, 32:679-682.

27. Campion J, Milagro Fl, Fernandez D, Martinez JA: Vitamin C supplementation influences body fat mass and steroidogenesis-related genes when fed a high-fat diet. Int J Vitam Nutr Res 2008, 78:87-95.

28. Baba S, Jacene HA, Engles JM, Honda H, Wahl RL: CT Hounsfield units of brown adipose tissue increase with activation: preclinical and clinical studies. J Nucl Med 2010, 51:246-250.

29. Astrup A, Bulow J, Madsen J: Interscapular brown adipose tissue blood flow in the rat. Determination with 133xenon clearance compared to the microsphere method. Pflugers Arch 1984, 401:414-417.

30. Vazquez-Vela ME, Torres N, Tovar AR: White adipose tissue as endocrine organ and its role in obesity. Arch Med Res 2008, 39:715-728.

doi:10.1186/2191-219X-1-2

Cite this article as: Hofman and Hicks: White fat, factitious hyperglycemia, and the role of FDG PET to enhance understanding of adipocyte metabolism. EJNMMI Research 2011 1:2

\section{Submit your manuscript to a SpringerOpen ${ }^{\mathcal{O}}$ journal and benefit from:}

- Convenient online submission

- Rigorous peer review

- Immediate publication on acceptance

- Open access: articles freely available online

- High visibility within the field

- Retaining the copyright to your article

Submit your next manuscript at $\gg$ springeropen.com 